\title{
Assessment of Learning Curve in Phacoemulsification Surgery Among the Eastern Province Ophthalmology Program Residents
}

This article was published in the following Dove Press journal: Clinical Ophthalmology

\author{
Mohanna Al-jindan' \\ Abdullah Almarshood ${ }^{2}$ \\ Sanaa A Yassin' \\ Khalid Alarfaj' \\ Ammar Al Mahmood ${ }^{3}$ \\ Naif $M$ Sulaimani ${ }^{3}$ \\ 'Department of Ophthalmology, Imam \\ Abdulrahman Bin Faisal University, \\ Dammam, Saudi Arabia; ${ }^{2}$ Department of \\ Ophthalmology, Qassim University, \\ Qassim, Saudi Arabia; ${ }^{3}$ Dhahran Eye \\ Specialist Hospital, Al-Dhahran 31942, \\ Saudi Arabia
}

Purpose: To assess residents' performance of phacoemulsification surgery and determine which steps of the procedure are most difficult to learn, and to measure rate of intraoperative complications.

Design: This was a prospective observational study.

Methods: Phacoemulsification surgery was divided into steps and each step was given a proficiency grade by the attending consultant. All intraoperative complications were recorded and analyzed.

Results: 200 cases performed by the Eastern Province ophthalmology program residents were evaluated. The most commonly encountered difficulty factors were hard nucleus (20.7\%), small pupil (12.6\%), and white cataract (10.3\%). Capsulorhexis, nucleus disassembly and removal, and cortex removal were the most difficult steps to learn. General complication rate was $17.5 \%$, and posterior capsular rupture was the most common complication (40\%). Proficiency more than $90 \%$ of the time in each step was noted in residents with prior experience of more than 40 cases, except for nucleus disassembly.

Conclusion: The study showed that nucleus disassembly remained the major obstacle in the residents' exponential learning curve of phacoemulsification surgery. Majority of complications occurred at level of capsulorhexis and cortical removal steps.

Keywords: phacoemulsification, learning curve, residents, training, complication rate

\section{Introduction}

Phacoemulsification surgery is one of the essential surgical requirements of residency training in ophthalmology. Developing microsurgical skills requires time and dedication. Studies on residents' learning curve in performing phacoemulsification showed that achieving surgical competency and efficiency required 70-80 phacoemulsification cases to obtain expert surgical skills. ${ }^{1,2}$ According to Saudi board ophthalmology curriculum, a minimum of 80 cases, as a main surgeon, are required to complete residency training. ${ }^{3}$ Teaching cataract surgery remains an ongoing challenge, considering both attaining a high level of training and maintaining patient safety. A stepwise introduction to surgical training usually begins with giving residents some steps of the surgery that can be in a sequential order, reverse order, or modular order (where mastering only one surgical step per case is mandatory before moving to the next step). ${ }^{2}$ Additionally, a selective order can be undertaken starting from the easiest steps to the most difficult one. Upon completion of all the steps, the resident is given the chance to do a full case surgery.
Correspondence: Sanaa A Yassin Department of Ophthalmology, Imam Abdulrahman Bin Faisal University, Dammam, Saudi Arabia

Email syassin@iau.edu.sa 
In the training program of ophthalmology in the Eastern Province, Saudi Arabia, residents start to learn phacoemulsification surgery by wet lab and simulator in their first year. In the second year they start to do the surgery in several steps and they are expected to do all the steps by the end of the year. In the third and fourth year they start to do a full case surgery.

Both teaching programs and patients' safety entail tracking and measuring the progress of residents' surgical performance. The learning curve can be determined considering several factors including; resident's experience, preoperative risk factors, ${ }^{4}$ incidence of complications, ${ }^{5}$ case duration, ${ }^{6}$ takeover rates, ${ }^{7-9}$ and proficiency scores for each surgical step. ${ }^{10}$ Even though there are several grading systems, none of them has proved to be superior to the other at improving the phacoemulsification learning curve. ${ }^{2}$

The aim of this study was to prospectively determine the proficiency of the program residents' performance of phacoemulsification surgery and to identify the most difficult steps to learn, at the same time intraoperative complications were monitored. This assessment is thought to help in evaluating and improving residents' surgical training.

\section{Method}

This was a prospective study that evaluated phacoemulsification performance of program residents between October 2014 and April 2015. The study was approved by the Dhahran Eye Specialist Hospital-Institutional Review Board and was conducted in accordance with the Declaration of Helsinki.

Residents' performance of phacoemulsification surgery was evaluated prospectively by giving residents a proficiency grade on each step of the surgery. Steps were also ranked according to the proficiency level from the easiest steps to the most difficult one. All intraoperative complications were monitored to assess the general rate as well as the rate for each step, and the level of case difficulty; straightforward versus non-straightforward cases were noted. A study form was developed for data collection (Appendix 1). All patient identifiers (eg, personal names and social security numbers) that directly or indirectly identified a person were not collected in the gathered data. Data Collection Form included the attending surgeon's name; the year level of the resident; patient's age and gender; resident's prior experience; difficulty level of the surgery; proficiency level for each step of the surgery; and complications. The surgery was divided into the following steps: wound construction, capsulorhexis, hydrodissection, nucleus sculpting, nucleus disassembly, nucleus removal, cortical removal, IOL folding, IOL insertion, viscoelastic removal, and wound integrity. Proficiency levels were based on whether each step could be performed successfully without assistance, with minimal assistance, with maximum assistance, or not done. Minimal assistance was defined to be less than $50 \%$ of the work, while maximum assistance was more than $50 \%$. Level of difficulty was based on whether the case was straightforward or had one or more difficulty factors. The attending consultant noted all complications as well as the step level of complication and whether it was corrected by the resident or the attending consultant.

Phacoemulsification surgeries were done by two different phacoemulsification machines including Alcon Laboratories: Infinity and AMO Whitestar Signature Phacoemulsifier. All cases were done basically by "stop and chop" technique. Local or general anesthesia was used determined by the case. Surgeries took place in two hospitals; both are located in the Eastern Province of Saudi Arabia.

Data were analyzed using IBM SPSS Statistics for Windows (Version 22.0. Armonk, NY: IBM Corp). Descriptive statistics were calculated for all variables. A proficiency level of each step was correlated with resident's experience level to assess the learning curve of the surgery.

\section{Results}

The study evaluated 200 cases that were done by program residents, $10.5 \%$ of cases were done by 10 junior residents (R1 -R2), while $89.5 \%$ of cases were done by 12 senior residents (R3-R4).

Demographic data revealed that $60 \%$ of patients were male and $40 \%$ were female. Mean age of the patients was $59.3 \pm 8.5$ years. Prior experience of the evaluated residents ranged from 0 to 65 cases, with mean $22.2 \pm 18.6$ cases. About $66 \%$ of the cases were straightforward, while 34\% of cases had one or more difficulty factors. The most commonly encountered difficulty factors were hard nucleus (20.7\%), small pupil (12.6\%), and white cataract $(10.3 \%)$. Other factors are listed in Table 1.

The most difficult steps to master were capsulorhexis, nucleus disassembly and removal, and cortical removal. On the other hand, wound construction; hydrodissection; IOL folding; IOL insertion; viscoelastic removal; and wound integrity were easier, as demonstrated in Tables 2 and 3.

Residents with prior experience of over 40 cases were rated proficient more than $90 \%$ of the time in each step, except for nucleus disassembly, as shown in Table 4. To assess residents' prior experience effect on proficiency, an ordinal logistic regression was performed for the 12 surgical steps. Residents' prior experience showed statistically significant 
Table I Number and Percentage of Difficulty Factors

\begin{tabular}{|l|l|l|}
\hline Difficulty Factor & Number of Cases & Percentage \\
\hline Hard Nucleus & 18 & $20.7 \%$ \\
Small Pupil & 11 & $12.6 \%$ \\
White cataract & 9 & $10.3 \%$ \\
Behavioral factors & 8 & $9.2 \%$ \\
Soft nucleus & 7 & $8.0 \%$ \\
Corneal haze & 7 & $8.0 \%$ \\
Loose zonule & 6 & $6.9 \%$ \\
High myopia & 5 & $3.4 \%$ \\
Deep-set eye & 3 & $3.4 \%$ \\
Hyperopia & 3 & $3.4 \%$ \\
Floppy iris & 2 & $2.3 \%$ \\
Positive back pressure & 2 & $2.3 \%$ \\
Anterior capsular fibrosis & 2 & $2.3 \%$ \\
Vitrectomized eye & 1 & $1.1 \%$ \\
Moving eye & 1 & $1.1 \%$ \\
Small palpebral fissure & 1 & $1.1 \%$ \\
Posterior synechia & 1 & $1.1 \%$ \\
\hline
\end{tabular}

association with capsulorhexis, hydrodissection, cortical removal, IOL insertion and viscoelastic removal with a p-value $=0.011,<0.001,0.040,<0.001,<0.001$ respectively.

The overall rate of complications was $17.5 \%$; $(95 \%$ Confidence Interval, $15 \%$ to $20 \%$ ). The most encountered complications were posterior capsule rupture (40\%) and anterior capsule extension (37.1\%). While the majority of complications were corrected by the attending consultant (85\%), a small percentage of complications were managed by the resident (15\%) as indicated in Table 5. Rate of complications was lower in straightforward cases $(12.9 \%)$ in comparison with non-straightforward cases (26.5\%). Investigation of complications per step revealed that capsulorhexis (40\%) and cortical removal $(22.9 \%)$ were the steps with highest rate of complications (Table 6).

\section{Discussion}

Residents' performance of phacoemulsification surgery has been evaluated by several studies using various measurement tools. ${ }^{1,4,5,9-15}$ Most of these studies were retrospective studies that used evaluation of the outcome and complications as a measurement tool, ${ }^{1,4,5,9,11-13}$ while few were prospective studies that evaluated intraoperative surgical proficiency level. ${ }^{10,14,15}$ To the best of our knowledge, no study has been done to evaluate our training program's residents (the Eastern province ophthalmology training program in Saudi Arabia). The proficiency grading system that was used in this study identified capsulorhexis, nucleus disassembly, nucleus removal, and cortex removal as the hardest steps to learn for our training residents. These results are compatible with that reported by Taravella et al $^{10}$ who evaluated nine residents in University of Colorado Hospital, considering total case time and a proficiency grade as the main outcome measures. Additionally, the current study showed capsulorhexis and cortical removal had the highest incidence of complications. Based on these data, an extra effort to practice these steps by wet labs and simulators is recommended before doing first cases.

Residents' previous experience had a positive impact on proficiency grades of each step, as those with prior experience of 40 cases or more had proficiency grade more than $90 \%$ of the time in each step, except for nucleus disassembly. The number of cases required by our residents to get high proficiency grade were much lower than

Table 2 Level of Residents' Proficiency at Each Surgical Step Is Presented in Percentage

\begin{tabular}{|c|c|c|c|c|}
\hline \multirow[t]{2}{*}{ Surgical Step } & \multicolumn{4}{|l|}{ Proficiency } \\
\hline & Not Done & Extensive Assistance & Minimal Assistance & Professionally \\
\hline Wound construction & $4.5 \%$ & 5.5 & - & $90 \%$ \\
\hline Capsulorhexis & $8 \%$ & $6 \%$ & $18 \%$ & $68 \%$ \\
\hline Hydrodissection & $10 \%$ & $2.5 \%$ & $7.5 \%$ & $80 \%$ \\
\hline Nucleus sculpting & $10.5 \%$ & $3.5 \%$ & $9 \%$ & $77 \%$ \\
\hline Nucleus disassembly & $14.5 \%$ & $5.5 \%$ & 15.5 & $64.5 \%$ \\
\hline Nucleus removal & $17 \%$ & $8.5 \%$ & $14.5 \%$ & $60 \%$ \\
\hline Cortical removal & $24.6 \%$ & $5.5 \%$ & $9 \%$ & $60.8 \%$ \\
\hline IOL folding & $25.5 \%$ & $2 \%$ & $0.5 \%$ & $72 \%$ \\
\hline IOL insertion & $23 \%$ & $2 \%$ & $4.5 \%$ & $70.5 \%$ \\
\hline Viscoelastic removal & $23 \%$ & $1 \%$ & $1 \%$ & $75 \%$ \\
\hline Wound integrity & $22.6 \%$ & $2.5 \%$ & $0.5 \%$ & $74.4 \%$ \\
\hline
\end{tabular}


Table 3 Ranking of Surgical Steps According to Proficiency, Excluding Steps That Were Not Done

\begin{tabular}{|l|l|l|l|}
\hline \multirow{2}{*}{ Surgical Steps } & \multicolumn{2}{l|}{ Level of Proficiency } & Professionally \\
\cline { 2 - 4 } & Extensive Assistance & Minimal Assistance & $97.4 \%$ \\
\hline Viscoelastic removal & $1.3 \%$ & $1.3 \%$ & $96.6 \%$ \\
IOL folding & $2.7 \%$ & $0.7 \%$ & $96.1 \%$ \\
Wound integrity & $3.2 \%$ & $0.6 \%$ & $94.2 \%$ \\
Wound construction & - & $5.8 \%$ & $91.6 \%$ \\
IOL insertion & $2.6 \%$ & $5.8 \%$ & $88.9 \%$ \\
Hydrodissection & $2.8 \%$ & $8.3 \%$ & $86.0 \%$ \\
Nucleus sculpting & $3.9 \%$ & $10.1 \%$ & $80.7 \%$ \\
Cortical removal & $7.3 \%$ & $12.0 \%$ & $75.4 \%$ \\
Nucleus disassembly & $6.4 \%$ & $18.1 \%$ & $73.9 \%$ \\
Capsulorhexis & $6.5 \%$ & $19.6 \%$ & $72.3 \%$ \\
Nucleus removal & $10.2 \%$ & $17.5 \%$ & \\
\hline
\end{tabular}

Table 4 Percentage of Residents Rated Proficient in Each Step - in Relation to Prior Experience

\begin{tabular}{|l|l|l|l|l|l|}
\hline \multirow{2}{*}{ Surgical Steps } & \multicolumn{4}{l|}{ Prior Experience } \\
\cline { 2 - 6 } & I-10 Cases (n=63) & II-20 Cases (n=33) & 2I-30 Cases (n=45) & 3 I-40 Cases (n=46) & >40 Cases (n= I2) \\
\hline Wound construction & $76 \%$ & $94 \%$ & $96 \%$ & $98 \%$ & $100 \%$ \\
Capsulorhexis & $49 \%$ & $55 \%$ & $78 \%$ & $85 \%$ & $100 \%$ \\
Hydrodissection & $65 \%$ & $88 \%$ & $87 \%$ & $83 \%$ & $100 \%$ \\
Nucleus sculpting & $62 \%$ & $76 \%$ & $82 \%$ & $87 \%$ & $100 \%$ \\
Nucleus disassembly & $48 \%$ & $48 \%$ & $76 \%$ & $85 \%$ & $83 \%$ \\
Nucleus removal & $41 \%$ & $39 \%$ & $78 \%$ & $76 \%$ & $92 \%$ \\
Cortical removal & $44 \%$ & $36 \%$ & $77 \%$ & $76 \%$ & $92 \%$ \\
IOL folding & $70 \%$ & $58 \%$ & $78 \%$ & $74 \%$ & $92 \%$ \\
IOL insertion & $62 \%$ & $58 \%$ & $80 \%$ & $78 \%$ & $92 \%$ \\
Viscoelastic removal & $68 \%$ & $67 \%$ & $82 \%$ & $78 \%$ & $92 \%$ \\
Wound integrity & $63 \%$ & $72 \%$ & $78 \%$ & $83 \%$ & $92 \%$ \\
\hline
\end{tabular}

Table 5 Number and Percentage of Encountered Complications

\begin{tabular}{|l|l|l|l|l|}
\hline Complication & Number of Cases & Percentage & Corrected by Attending Consultant & Corrected by Resident \\
\hline Posterior capsular rupture & 14 & $40 \%$ & $12 / 14$ & $2 / 14$ \\
Anterior capsule extension & 13 & $37.1 \%$ & $10 / 13$ & $3 / 13$ \\
Converted to ECCE & 2 & $5.7 \%$ & $2 / 2$ & - \\
Descemet detachment & 2 & $5.7 \%$ & $2 / 2$ & - \\
Small capsulorhexis & $\mathrm{I}$ & $2.9 \%$ & $\mathrm{I} / \mathrm{I}$ & - \\
Bite of anterior capsule & $\mathrm{I}$ & $2.9 \%$ & $\mathrm{I} / \mathrm{I}$ & - \\
Iridodialysis & $\mathrm{I}$ & $2.9 \%$ & $\mathrm{I} / \mathrm{I}$ & - \\
Dropped lens fragments & $\mathrm{I}$ & $2.9 \%$ & $\mathrm{I} / \mathrm{I}$ & - \\
\hline
\end{tabular}

that reported by Taravella et $\mathrm{al}^{10}$ of 75 cases. This disagreement in results can be attributed to lack of consideration of the case times in the current study. However, nucleus disassembly and removal appeared to remain as a persisting difficulty even after 75 surgeries.
The overall complication rate $(17.5 \%)$ is comparable to rates reported in the literature for resident-performed phacoemulsification (1.8-27.4\%). ${ }^{1,5,8,9,12,16-18}$ Majority of complications, $63 \%$, occurred in cases done by senior residents (R3). This observation is similar to results reported by Mangan et $\mathrm{al}^{9}$ 
Table 6 Step Level of Complications

\begin{tabular}{|l|l|}
\hline Step of Complication & Percentage \\
\hline Capsulorhexis & $40 \%$ \\
Cortical removal & $22.9 \%$ \\
Nucleus disassembly & $11.4 \%$ \\
Nucleus removal & $5.7 \%$ \\
Undetermined & $20 \%$ \\
\hline
\end{tabular}

where complications were reported to be higher in residents with more experience (61-120 cases). The complications rate increase was attributed to the decrease of intervention rates of the supervising attending consultant in this group. ${ }^{9}$ Posterior capsular rupture, the most common complication, occurred in $14(7 \%)$ cases. This rate is consistent with rates reported in other training programs $(2.6-9.9 \%) ., 5,11,19$ However, it is higher than the rate reported by experienced ophthalmologists $(0.45-2.5 \%){ }^{20-22}$ Anterior capsular extension occurred in 13 cases $(6.5 \%)$, while small capsulorhexis was documented in 1 case $(0.5 \%)$. Residents tend to make bigger diameter capsulorhexis rather than smaller, which is more difficult to correct. Proper sizing of the capsulorhexis should be continuously monitored and guided based on the available landmarks. Dropped lenticular fragments in posterior segment, a serious complication, occurred in 1 case $(0.5 \%)$, which is in agreement with rates reported in other studies $(0.9-1.1 \%)^{4,9,23}$

Additional main outcome in this study was the difference in the rate of complications in straightforward versus non-straightforward cases. Complication rate was found to be twofold in the presence of one or more difficulty factor in surgery, compared to straightforward cases $(26.5 \%$ vs $12.9 \%$ respectively). Rutar et $\mathrm{al}^{4}$ and Blomquist et $\mathrm{al}^{24}$ reported an increase in complication rate in surgeries performed by residents in the presence of difficulty factors such as hard nucleus or weak zonules. Up to one third of the evaluated cases were non-straightforward, which is considered a high percentage. Residents are encouraged to be more selective in their cases in order to improve the outcome and decrease the load of complications.

One of the limitations of our study is the subjective nature of assessment and grading of proficiency level. Nine consultants participated in residents' evaluation, and their evaluation may differ from one to another. We considered this issue by defining minimal assistance as less than fifty percent of the work; extensive assistance as more than fifty percent; and proficiency as no assistance. However, we recommend a more objective evaluation system for future assessments.
The second limitation is that some steps of the surgery may not be offered to the trainee by the attending. This may occur in an anticipation of compromising patient safety or following a serious complication, in addition to other factors that are not related to resident performance. It might occur with any resident; whatever his level and experience. Since we do not have a documented explanation for the steps that were not given, we depended on the steps that were done on assessing proficiency level. It would be more informative if these steps were explained whether related to resident factors or not, and to be part of the evaluation. Lastly, the use of different phacoemulsification machines may influence the surgical efficiency and outcomes. ${ }^{25}$

In conclusion, evaluation of our residents revealed that capsulorhexis, nucleus disassembly and removal, and cortex removal were among the hardest steps to learn. Majority of complications occurred at level of capsulorhexis and cortical removal steps. Focusing on these highlighted steps by wet-lab practice and simulators before operating on actual patients would maximize proficiency and minimize complications. Additionally, proper selection of straightforward cases should be encouraged, in order to improve the outcome and decrease the rate of complications. Finally, it is recommended to adopt a more objective evaluation system for future assessments.

\section{Disclosure}

The authors report no conflicts of interest in this work.

\section{References}

1. Randleman JB, Wolfe JD, Woodward M, Lynn MJ, Cherwek DH, Srivastava SK. The resident surgeon phacoemulsification learning curve. Arch Ophthalmol. 2007;125(9):1215-1219. doi:10.1001/archopht.125. 9.1215

2. Kaplowitz K, Yazdanie M, Abazari A. A review of teaching methods and outcomes of resident phacoemulsification. Surv Ophthalmol. 2017;63(2).

3. Tabbara K, AL Debasi T, AL Dohayan N, AL Fawaz A. Saudi Board Ophthalmology Curriculum. Specialties SCfH, editor. Riyadh: Saudi Commission for Health Specialties; 2014.

4. Rutar T, Porco TC, Naseri A. Risk factors for intraoperative complications in resident-performed phacoemulsification surgery. Ophthalmology. 2009;116(3):431-436. doi:10.1016/j.ophtha.2008.10.028

5. Corey RP, Olson RJ. Surgical outcomes of cataract extractions performed by residents using phacoemulsification. J Cataract Refract Surg. 1998;24(1):66-72. doi:10.1016/S0886-3350(98)80076-X

6. Wiggins MN, Warner DB. Resident physician operative times during cataract surgery. Ophthalmic Surg Lasers Imaging. 2010;41 (5):518-522. doi:10.3928/15428877-20100726-07

7. Briszi A, Prahs P, Hillenkamp J, Helbig H, Herrmann W. Complication rate and risk factors for intraoperative complications in residentperformed phacoemulsification surgery. Graefes Arch Clini Exp Ophthalmol. 2012;250(9):1315-1320. doi:10.1007/s00417-012-2003-y 
8. Lee JS, Hou CH, Yang ML, Kuo JZ, Lin KK. A different approach to assess resident phacoemulsification learning curve: analysis of both completion and complication rates. Eye (Lond). 2009;23(3):683-687. doi: $10.1038 /$ sj.eye. 6703103

9. Mangan MS, Atalay E, Arici C, Tuncer I, Bilgec MD. Comparison of different types of complications in the phacoemulsification surgery learning curve according to number of operations performed. Turk J Ophthalmol. 2016;46(1):7-10. doi:10.4274/tjo.83788

10. Taravella MJ, Davidson R, Erlanger M, Guiton G, Gregory D. Characterizing the learning curve in phacoemulsification. J Cataract Refract Surg. 2011;37(6):1069-1075. doi:10.1016/j.jcrs.2010.12.054

11. Cruz OA, Wallace GW, Gay CA, Matoba AY, Koch DD. Visual results and complications of phacoemulsification with intraocular lens implantation performed by ophthalmology residents. Ophthalmology. 1992;99 (3):448-452. doi:10.1016/S0161-6420(92)31954-2

12. Allinson RW, Metrikin DC, Fante RG. Incidence of vitreous loss among third-year residents performing phacoemulsification. Ophthalmology. 1992;99(5):726-730. doi:10.1016/S0161-6420(92)31904-9

13. Albanis CV, Dwyer MA, Ernest JT. Outcomes of extracapsular cataract extraction and phacoemulsification performed in a university training program. Ophthalmic Surg Lasers. 1998;29(8):643-648.

14. Dooley IJ, O'Brien PD. Subjective difficulty of each stage of phacoemulsification cataract surgery performed by basic surgical trainees. J Cataract Refract Surg. 2006;32(4):604-608. doi:10.1016/ j.jcrs.2006.01.045

15. Carricondo PC, Fortes AC, Mourao Pde C, Hajnal M, Jose NK. Senior resident phacoemulsification learning curve (corrected from cure). Arq Bras Oftalmol. 2010;73(1):66-69. doi:10.1590/S000427492010000100012

16. Allinson RW, Palmer ML, Fante R, Stanko M. Vitreous loss during phacoemulsification by residents. Ophthalmology. 1992;99(8):1181. doi:10.1016/S0161-6420(92)31830-5
17. Badoza DA, Jure T, Zunino LA, Argento CJ. State-of-the-art phacoemulsification performed by residents in Buenos Aires, Argentina. $J$ Cataract Refract Surg. 1999;25(12):1651-1655. doi:10.1016/ S0886-3350(99)00270-9

18. Tayanithi P, Pungpapong K, Siramput P. Vitreous loss during phacoemulsification learning curve performed by third-year residents. J Med Assoc Thai. 2005;88(Suppl 9):S89-S93.

19. Zimmer DV, Harrison JC, Carriere VM. Cataract extraction with lens implantation at Biloxi Veterans Affairs Medical Center: experience of ophthalmology residents. Ann Ophthalmol. 1994;26(2):47-49.

20. Pingree MF, Crandall AS, Olson RJ. Cataract surgery complications in 1 year at an academic institution. J Cataract Refract Surg. 1999;25 (5):705-708. doi:10.1016/S0886-3350(99)00017-6

21. Gimbel HV, Sun R, Ferensowicz M, Anderson Penno E, Kamal A. Intraoperative management of posterior capsule tears in phacoemulsification and intraocular lens implantation. Ophthalmology. 2001;108(12):2186-2189; discussion 2190-2182. doi:10.1016/S0161-6420(01)00716-3

22. Ang GS, Whyte IF. Effect and outcomes of posterior capsule rupture in a district general hospital setting. J Cataract Refract Surg. 2006;32 (4):623-627. doi:10.1016/j.jcrs.2006.01.047

23. Bhagat $\mathrm{N}$, Nissirios $\mathrm{N}$, Potdevin $\mathrm{L}$, et al. Complications in resident-performed phacoemulsification cataract surgery at New Jersey Medical School. Br J Ophthalmol. 2007;91(10):1315-1317. doi:10.1136/bjo.2006.111971

24. Blomquist PH, Sargent JW, Winslow HH. Validation of Najjar-Awwad cataract surgery risk score for resident phacoemulsification surgery. J Cataract Refract Surg. 2010;36(10):1753-1757. doi:10.1016/j.jcrs.2010.04.035

25. DeMill DL, Zaugg BE, Pettey JH, et al. Objective comparison of 4 nonlongitudinal ultrasound modalities regarding efficiency and chatter. $J$ Cataract Refract Surg. 2012;38(6):1065-1071. doi:10.1016/j.jcrs. 2011.12.040
Clinical Ophthalmology

\section{Publish your work in this journal}

Clinical Ophthalmology is an international, peer-reviewed journal covering all subspecialties within ophthalmology. Key topics include: Optometry; Visual science; Pharmacology and drug therapy in eye diseases; Basic Sciences; Primary and Secondary eye care; Patient Safety and Quality of Care Improvements. This journal is indexed on PubMed

\section{Dovepress}

Central and CAS, and is the official journal of The Society of Clinical Ophthalmology (SCO). The manuscript management system is completely online and includes a very quick and fair peer-review system, which is all easy to use. Visit http://www.dovepress.com/ testimonials.php to read real quotes from published authors. 